\title{
INSTINTO, ETOLOGIA E A TEORIA DE KONRAD LORENZ
}

\section{Instinct, Etology and the Konrad Lorenz theory}

\author{
Átima Clemente Alves Zuanon ${ }^{1}$
}

Resumo: O presente artigo tem como objetivo apresentar um pouco da evolução da ciência que estuda o comportamento animal comparado - Etologia -, destacando a teoria de Lorenz (1937), considerado um dos fundadores dessa ciência. O texto inicia-se fazendo referência às diversas relações existentes entre os seres humanos e os demais animais, desde os primórdios da existência humana. Em seguida, aborda o aspecto histórico da evolução do conceito de instinto, como tema marcante da teoria de Lorenz (1937). Relata as críticas entre os estudiosos de áreas afins e aponta as novas tendências acerca do estudo do comportamento animal, bem como suas contribuições que hoje permeiam as várias áreas do conhecimento.

Palavras-chave: Aprendizado. Etologia. Instinto. Lorenz. Reflexo.

\begin{abstract}
The purpose of this paper is to discuss the evolution of science that studies comparative animal behaviour - Etology -, highlighting the theory of Lorenz (1937), considered one of the founders of this science. The text begins by making reference to the diverse relationships existing between man and other animals from the beginning of human being existence. After that, it approaches the historical aspect of the evolution of the concept of instinct as a feature of Lorenz's theory (1937), followed by the criticism among scholars and points out new trends concerning the study of animal behavior, as well as its contributions, that are today contributing to other areas of knowledge.
\end{abstract}

Key words: Learning. Etology. Instinct. Lorenz. Reflex.

\footnotetext{
${ }^{1}$ Bacharel e Licenciada em Ciências Biológicas; mestre em Educação para a Ciência; professora de Biologia, Colégio de Aplicação da Universidade Federal de Viçosa. Viçosa, MG. <atimazua@ufv.br>
}

\footnotetext{
${ }^{1}$ Universidade Federal de Viçosa

Av. PH Rolfs s/n.

Viçosa, MG

36.570-000
}

337 


\section{Introdução}

Desde os tempos mais remotos, a familiarização com o comportamento animal foi essencial para que o homem obtivesse recursos alimentares para sua sobrevivência. Para o homem, conhecer os hábitos de alguns animais significava saber os momentos e os locais certos para pescar ou caçar, bem como se defender dos predadores. As estratégias de caça e de pesca dependiam do tamanho e/ou de como as presas se comportavam.

No alvorecer de nossa civilização, aproximadamente há 12 mil anos, a humanidade passou a dominar técnicas elaboradas para obtenção das fontes de alimentos e iniciou o processo de domesticação de plantas e de animais, por meio da agricultura e da pecuária (AMABIS e MARTHO, 2005). Atualmente, tecnologias sofisticadas, associadas à tecnociência, são utilizadas para explorar novos recursos ambientais. Além disso, vale salientar que os animais desempenham papéis importantes na formação cultural dos povos de todo o mundo, seja como elementos de cultuação religiosa, parceiros de trabalho ou, ainda, como animais de companhia. Outro tipo de relação que o ser humano estabelece com os demais seres vivos advém do interesse por compreendê-los pela metodologia científica, procurando caracterizar fenômenos biológicos por intermédio de procedimentos dedutivos e experimentais, propondo leis e teorias que tentam explicar diferentes aspectos da vida animal.

A preocupação com os processos comportamentais é bastante antiga. No século IV a.C., Aristóteles já havia publicado obras sobre a origem, a reprodução, a anatomia e o movimento dos animais. Cunha (1983) menciona que Descartes (1641) foi considerado um inspirador inicial ao conceber o mecanismo natural do reflexo como uma explicação do comportamento animal, inclusive do comportamento humano, em que não houvesse a intervenção da razão. Ao separar radicalmente o espírito e o corpo como duas ordens incomensuráveis de substâncias, ele contribuiu para o avanço da ciência do comportamento, dividida em dois ramos: psicológico e biológico que, freqüentemente ao longo da história, ora se chocam ora se aproximam.

A psicologia, concentrando seu interesse nos seres humanos, passou a estudar o comportamento animal como forma de esclarecer problemas humanos que não poderiam ser estudados diretamente no mesmo (CUNHA, 1983). A evolução dos estudos acerca da compreensão biológica do comportamento, bem como da psicologia comparada, foi inspirada nas obras de Darwin, que formulou os princípios da evolução orgânica. Darwin só não foi considerado fundador da etologia (ciência que estuda o comportamento animal comparado), pelo fato de o comportamento animal não deixar fósseis, apenas alguns traços - caracteres - morfológicos dos organismos (CUNHA, 1983).

Um dos primeiros pesquisadores que influenciou ambos os ramos foi William James. Em 1890, ele publicou o livro Principles of Psychology, o qual aborda os conceitos de instintos e reflexos. Notou que os instintos não eram fixos, e sim variações comportamentais que tendem a se repetir, apresentando média consideravelmente constante (GRIER, 1984).

Durante a maior parte do século XX, a etologia e a psicologia animal se desenvolveram independentemente (RICHARDS, 1987 citado por SHETTLEWORTH, 2001). Existem várias razões para explicar a pequena comunicação entre os dois campos: a) A etologia se desenvolveu inicialmente por intermédio de zoólogos na Europa, enquanto a psicologia animal se desenvolveu, em sua maior parte, na América do Norte. b) Os etologistas trabalharam 
na perspectiva da teoria evolucionária, ao passo que a psicologia, em geral, estava fora de contato com o pensamento evolucionário, ou mesmo em oposição a ele (PLOTKIN, 1997, e GALEF, 1998 citados por SHETTLEWORTH, 2001). c) Os etologistas focalizaram o comportamento inato de animais no campo, enquanto os psicólogos estudaram comportamentos aprendidos de poucas espécies nos laboratórios. Desse modo, os etologistas têm se preocupado com questões comportamentais que levam em conta os aspectos funcionais e evolutivos, enquanto mecanismos como percepção, aprendizado, entre outros aspectos de cognição, têm sido, tradicionalmente, apresentados sob os domínios da psicologia.

\section{Histórico da evolução do conceito de instinto}

Hess (1975) relata que antigos pesquisadores, tais como o zoólogo alemão Barão von Pernau (1707), o naturalista francês Antoine Ferchault Réaumur (1734), os naturalistas ingleses Charles Darwin (1872) e Douglas Spalding (1873), e, posteriormente, os zoólogos americanos Charles Otis Whitman (1898), Herbert Spencer Jennings (1904), Wallace Craig (1918) e, ainda, o zoólogo alemão Jacob von Uexküll (1909), estudaram cientificamente o comportamento não-aprendido de animais.

Cunha (1983) destaca a importância do trabalho de pesquisadores como Whitman (1898) e Oskar Heinroth (1910) que, ao estudarem, independentemente, o comportamento de aves, concluíram que instintos e órgãos devem ser estudados do ponto de vista comum da descendência filogenética; e apontaram a possibilidade de aplicação do conceito de homologia ${ }^{2}$ não só a caracteres morfológicos, mas também a padrões comportamentais. $\mathrm{O}$ autor ainda comenta que Craig, em 1918, teria sido o primeiro cientista a ir além do estágio descritivo dos comportamentos, elaborando uma teoria em que o comportamento instintivo abrangeria duas fases distintas: comportamento apetitivo e comportamento consumatório. A fase apetitiva consiste de um comportamento de busca inicialmente variável, que vai se tornando mais específico até que o ato consumatório seja executado em resposta a uma situação liberadora de estímulos. O comportamento apetitivo é variável e plástico, enquanto o ato consumatório é relativamente fixo e estereotipado. ${ }^{3}$ Segundo Hess (1975), Craig destacou a noção de que o comportamento apetitivo é acompanhado por certa prontidão para a ação, e que muitos dos padrões de comportamento executados durante o ato apetitivo não são inatos, e sim aprendidos, porém a ação final, ou seja, o ato consumatório é sempre inato.

\footnotetext{
${ }^{2}$ Propriedades de estruturas biológicas com uma origem evolutiva comum, mesmo que tais estruturas possam não desempenhar as mesmas funções. Ou ainda, "uma propriedade relativa a entidades que tenham uma origem comum, em um ancestral comum” (MATIOLI, 2001, p. 131).

${ }^{3}$ O que é sempre o mesmo, que não varia, fixo, inalterável (Ferreira, 1995).
} 
Nenhum desses pesquisadores formulou uma hipótese relativa à natureza fisiológica de sua descoberta (LORENZ, 1995). Segundo Cunha (1983), Lorenz foi o primeiro cientista a ver claramente o significado teórico dessas idéias e relacioná-las a uma teoria integrada do comportamento animal, que já continha as noções: $a$ ) de bloqueio central das ações; $b$ ) de mecanismo de desencadeamento inato e $c$ ) de acumulação endógena de um potencial específico de ação. Essas, em conjunto, servem de base para ordenar e interpretar os fatos, como também delinear investigações empíricas mais detalhadas.

Antes de Darwin, acreditava-se que o "conhecimento" demonstrado pelos animais, em seu comportamento inato, havia sido implantado pelo Criador. Com a teoria de Darwin, surgiu a noção de transmissão desse comportamento inato de uma geração para outra por meio da hereditariedade (HESS, 1975).

Influenciados pelos relatos sobre o comportamento animal apresentados por Darwin, os naturalistas estabeleceram um conjunto de metodologias científicas e propuseram uma ciência denominada ETOLOGIA (do grego ethos, costume, e, logus, tratado) ou a ciência que estuda o comportamento animal comparado. Devemos, aos cientistas Konrad Lorenz, Níkolaas Tinbergen e Karl von Frish, a fundamentação teórica da Etologia, cujo marco foi em 1935, com a publicação da obra de Lorenz intitulada $O$ companheiro como fator no ambiente da ave, onde muitas de suas idéias já se achavam delineadas (CUNHA, 1983). No entanto, somente em 1973, Lorenz, Tinbergen e von Frish, considerados os fundadores da Etologia, tiveram o merecido reconhecimento da comunidade científica, tendo sido agraciados com o Prêmio Nobel.

Durante o final do século XIX e início do século XX, o uso indiscriminado e exagerado do termo "instinto", por muitos psicólogos, reduziu o termo a uma explicação generalizada para comportamentos que não eram bem compreendidos. A reação à utilização imprópria do termo fez com que o conceito de instinto ou comportamento inato fosse completamente negado por psicólogos atraídos pela teoria behaviorista de Watson (1928, 1922 citado por HESS, 1975), que pretendia explicar o comportamento com base em simples relações entre o indivíduo e o ambiente. Esses psicólogos, vindos de uma linha filosófica empiricista, com ênfase na determinação do ambiente no comportamento, mostravam-se coerentes com sua formação, uma vez que o conceito de reflexo (original ou adquirido) era essencialmente uma interpretação de como o meio ambiente controla o comportamento (CUNHA, 1965). Essas orientações, conjuntamente com as realizações de estudos de comportamento animal em laboratório, contribuíram para o surgimento do movimento ambientalista conhecido como Movimento Antiinstinto, que dominou a psicologia americana entre 1920 e 1940.

De acordo com Lorenz (1995), ocorria uma disputa ideológica entre escolas de psicologia, em que se percebiam duas diferentes linhas de pensamento: a) A escola de psicologia objetivista, representada por William MacDougal, que defendia ser o instinto um fator extranatural, inacessível, sendo, portanto, desnecessária qualquer explicação. Para os defensores dessa idéia, tudo o que os animais faziam era na busca de um determinado propósito, estabelecido por seus instintos extranaturais e infalíveis; b) Para a escola Behaviorista de Psicologia, essa concepção anteriormente mencionada era considerada como não científica, o que levava a exigir explicações causais para tal. Os behavioristas consideravam a experimentação controlada como único elemento que daria legitimidade ao conhecimento científico, não valorizando a observação simples (natural), e defendendo suas metodologias como sendo perfeitas para 
concentrar-se nos estudos do comportamento animal, inclusive humano, o que levou ao monismo explicativo.

Houve uma dicotomia muito clara dos dois grupos, pois enquanto um adotava uma versão mística de instinto, o outro chegava, até mesmo, a negar sua existência e, dogmaticamente, declarava que todo o comportamento era aprendido. Os psicólogos objetivistas, que pareciam estar cientes de ocorrências de padrões comportamentais inatos, descartavam qualquer tentativa de explicação. Apesar de concordar com as críticas feitas pelos behavioristas, em relação às opiniões sustentadas pelos psicólogos objetivistas, Lorenz (1965) considera essas afirmações falsas e destaca um erro embutido no pensamento behaviorista, que dizia que somente os processos de aprendizado podiam ser examinados experimentalmente e, dessa forma, concluíam (os behavioristas) erroneamente que todo comportamento deveria ser aprendido.

A primeira tentativa para o estabelecimento de critérios para se identificar um comportamento como inato ou não considera que o comportamento deveria ser não aprendido, característico da espécie e adaptativo. A aplicação desses critérios mostra-se, contudo, muito difícil (DETHIER e STELLAR, 1988).

Dethier e Stellar (1988) sugerem que os atos instintivos são desencadeados pelos efeitos combinados dos estímulos externos, hormônios e influências nervosas centrais excitatórias. A investigação dos estímulos externos geralmente mostra que eles são padrões temporais e espaciais complexos, que podem ser analisados em componentes específicos chamados "sinais-estímulos". Estes podem ser aspectos físicos do ambiente, como: luz, temperatura da água, vegetação etc. Quando os "sinais-estímulos" são produzidos pelo comportamento de outro animal, temos uma base inata para interações e organizações sociais. A combinação da teoria associativa de Wundt (1922) com a teoria da reflexologia de Pavlov (1927) facilitou a abstração de um mecanismo comportamental chamado reflexo condicionado, cujas qualidades o marcaram como ideal para a pesquisa experimental dos behavioristas (LORENZ 1995). Pavlov (1927) fez a contenção de um cão, soprou pó de carne repetidamente na sua boca e registrou precisamente a quantidade de saliva produzida. Então, o cientista associou o som de uma campainha com o pó de carne, repetindo esse procedimento muitas vezes, a intervalos sucessivos. Os pareamentos sucessivos da campainha com o pó de carne provocaram a salivação. Ao descrever essa experiência, Pavlov (1927) chamou a salivação, sob a influência da campainha, de reflexo condicionado; a campainha, de estímulo condicionado; a salivação, sob a influência da carne, de reflexo não-condicionado; e a própria carne, de estímulo não-condicionado. A mesma experiência foi repetida muitas vezes com animais diferentes e com muitos estímulos e respostas diferentes (DETHIER e STELLAR, 1988).

Segundo Miller (1962 citado por CUNHA, 1983), essas descobertas introduziram um método analítico em lugar do estudo ecológico dos animais em seu ambiente natural. Parecia mais fácil e aconselhável estudar os elementos básicos do comportamento num laboratório, onde as condições podiam ser convenientemente controladas e as medidas tomadas com mais precisão, do que afastar todas as variáveis imprevisíveis que podiam influenciar no ambiente natural. O termo instinto só foi reintroduzido no vocabulário científico quando os trabalhos de campo foram retomados e os etólogos europeus, inclusive Lorenz, acumularam novas provas da existência de padrões complexos de comportamento que não podiam ser considerados reflexivos, nem adquiridos por condicionamento (ROSS e DENENBERG, 1960). 


\section{A teoria de Konrad Lorenz}

Konrad Lorenz nasceu em Viena - Áustria, no ano de 1903, e morreu em 1989. Doutor em medicina e fisiologia, também se dedicou à zoologia e à psicologia comparada, sendo considerado um dos fundadores da ciência Etologia.

Sob orientação do anatomista vienense Ferdinand Hochestetter, Lorenz, valendo-se dos conhecimentos de metodologias e dos procedimentos utilizados para estudos de comparação filogenética, entendeu que os métodos empregados na morfologia comparativa eram perfeitamente aplicáveis ao comportamento de muitas espécies de peixes e pássaros. Posteriormente, Lorenz encontrou Heinroth, que já havia feito tal descoberta e, no início da década de 1930, ambos ficaram sabendo que Whitman chegara às mesmas conclusões, há dez anos (LORENZ, 1995).

Lorenz (1935), trabalhando com gansos e patos sob orientação de Hienroth, percebeu que os movimentos inatos e de valor para a taxonomia, identificados por Whitman e Heinroth, eram a mesma coisa que os movimentos estereotipados do comportamento compensatório, destacados por Craig. Lorenz (1935) denominou esses comportamentos de movimentos endógenos ou, ainda, movimentos instintivos. Mais tarde, esses movimentos, ou melhor, essas coordenações motoras, passaram a ser conhecidas como padrões fixos de ação, padrões fixos, ou, apenas, ação fixa (CUNHA, 1983).

Lorenz (1965) diferenciou instinto de aprendizagem, sustentando que os instintos eram inatos e não dependiam de experiência, enquanto a aprendizagem era o oposto - comportamento totalmente adquirido como resultado da experiência do individuo. Em vista da teoria adotada, entre 1910 e 1940, pelos psicólogos behavioristas, zoólogos e fisiologistas mecanicistas, segundo a qual o reflexo inato ou condicionado era a unidade fundamental de todos os comportamentos complexos, Lorenz (1965) procurou estabelecer as diferenças entre reflexos e padrão fixo de ação (CUNHA, 1983). Assim, ele descreve a diferença entre reflexo e instinto, destacando que apenas instinto é consumatório e, portanto, precedido de uma atividade apetitiva, enquanto reflexo requer um eliciador específico, apresenta uma fase refratária e uma proporcionalidade entre resposta e estimulação. O movimento instintivo ocorre, por vezes, "no vácuo", ou, mesmo, por partes, e depende do tempo transcorrido desde a última ocorrência. Se esse tempo é longo, pode-se desencadear o movimento com uma estimulação mínima. Se, ao contrário, é breve, poderá ser necessário estimular o organismo fortemente para se obter, por vezes, apenas os primeiros movimentos da seqüência típica, ou, mesmo, não obtê-los. Em contrapartida, nada disso ocorre com o reflexo (CUNHA, 1983).

Assim, Lorenz (1965) demonstrou a geração endógena e o bloqueio interno dos padrões fixos de ação. Com base em suas observações, percebeu que a ocorrência de um padrão fixo de ação estava relacionada a duas condições: o tempo transcorrido desde a última ocorrência do padrão e o aparecimento de estímulos específicos adequados. Na verdade, era possível compensar a adequação dos estímulos, privando o animal da oportunidade de exibir seus movimentos instintivos. Quanto mais tempo estivesse o animal privado da oportunidade de realização de uma coordenação motora, maior seria a probabilidade de que a apresentasse diante de meros pedaços, ou modelos grosseiros simulando a situação. Com base em relatos experimentais, Lorenz (1965) concluiu que, em condições de privações de estimulação eficaz, era gerada e acumulada continuamente uma energia no sistema nervoso do animal, até que um 
estímulo preciso (estímulo-sinal), atuando sobre o mecanismo de represamento (mecanismo inibidor do comportamento), desencadeasse o comportamento instintivo. Tal energia, postulada por Lorenz (1965), para descrever o surgimento de motivação para um padrão comportamental em particular, foi denominada de Energia Específica de Ação ou Potencial Específico de Ação (GRIER, 1984).

Colocando juntos o estímulo-sinal e o padrão fixo de ação, Lorenz (1965) formulou o conceito de mecanismo desencadeador inato. $\mathrm{O}$ estímulo-sinal supostamente desencadeia o padrão fixo de ação por meio do mecanismo desencadeador inato, deixando de haver a ação inibitória de centros nervosos superiores (GRIER, 1984). Para expressar didaticamente as várias relações supostas em sua teoria, Lorenz, em 1950, recorreu ao modelo hidromecânico ou "psico-hidráulico", representado, a seguir, na figura 1a. O modelo não foi desenvolvido para representar exatamente o que estava acontecendo dentro do sistema nervoso, mas apenas serviu como uma analogia (GRIER, 1984). O Modelo "Psico-hidráulico", proposto por Lorenz (1950), foi elaborado para tentar explicar os processos fisiológicos envolvidos na preparação e realização de um determinado comportamento. O nível da água (altura da coluna) representa o nível de Potencial Específico de Ação para realizar um comportamento que se encontra inibido; a torneira, enchendo o reservatório, representa uma fonte de estímulo endógeno; a válvula, em espiral na base do reservatório, representa o mecanismo desencadeador inato que atua inibindo a realização do comportamento, e a força aplicada sobre a válvula em espiral representa a ação de estímulos externos (ambientais).

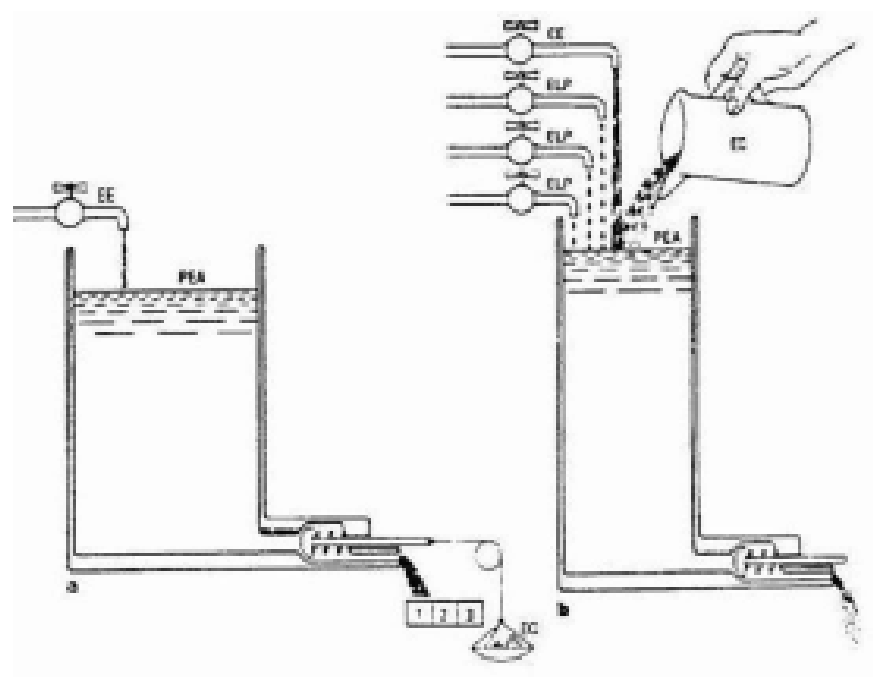

Figura 1. a Modelo "psico-hidráulico" original elaborado por Lorenz (1950); b Modelo "psicohidráulico" modificado em 1981 (LORENZ, 1995). 


\section{Conseqüências da teoria de Lorenz}

A teoria de Lorenz trouxe grande contribuição para o entendimento do conceito de instinto, ganhando respeitabilidade científica. No entanto, não promoveu a recuperação pura e simples do antigo conceito, mas reformulou-o, livrando-o das restrições feitas a seu emprego na ciência do comportamento pelos objetivistas, mecanicistas e behavioristas. Com a demonstração de que o padrão fixo é o núcleo da ação instintiva e corresponde ao acionamento de um mecanismo construído filogeneticamente, cessa o motivo para encará-lo, como faziam os objetivistas, como um misterioso poder de encaminhar-se para um resultado futuro complexo e biologicamente útil. Da mesma maneira, a determinação endógena do padrão fixo de ação - de natureza diferente dos reflexos incondicionados, não derivados dos reflexos por condicionamento e nem por isso deixando de corresponder a mecanismos nervosos, cessa o motivo para os psicólogos behavioristas, zoólogos e fisiólogos mecanicistas rejeitarem-no como não científico. Assim, esses cientistas são levados a admitir o padrão fixo de ação como mais uma unidade herdada ao lado de outras unidades fundamentais do comportamento: reflexo e condicionamento (CUNHA, 1983).

Importantes generalizações sobre instinto são provenientes dos trabalhos de Lorenz, von Frish, Tinbergen e de vários outros naturalistas. A expressão de comportamentos particulares em muitas espécies é notavelmente estereotipada ou relativamente constante entre todos os indivíduos de uma mesma idade e sexo, sobre circunstâncias similares (GRIER, 1984).

Segundo Cunha (1983), a identificação do padrão fixo de ação, conceito elaborado por Lorenz, é freqüentemente apontada como o fato que permitiu à etologia progredir rápida e seguramente. Isso porque se trata de um elemento de comportamento facilmente identificável, mesmo quando constituindo uma coordenação motora complexa. Como já foi identificado, por ser estereotipado, esse padrão de comportamento constitui uma base excelente para os estudos filogenéticos. Além disso, sua identificação permite, prontamente, um trabalho de descrição, categorização e circunstanciação, e, também, a realização de experimentos simples para a verificação de aspectos do meio que são capazes de desencadeá-lo.

A teoria de Lorenz teve um efeito estimulante imediato em muitos zoólogos e psicólogos europeus, entre os quais se destacam: Timbergen, Baerends, Thorpe, Hinde, Morris, Bibl-Eibesfeldt, Fabricius etc. Esses estudiosos contribuíram com novas demonstrações dos conceitos lorenzianos, com novas interpretações, expandindo assim a base empírica e o quadro conceitual da referida ciência (CUNHA, 1983).

Segundo Grier (1984), todos os conceitos mais antigos e as tentativas de se compreender o que ocorre com o animal, embora amplamente rejeitados ou substituídos por conceitos mais recentes, ajudaram a organizar e categorizar observações. Esses conceitos levaram ao progresso e a revisões de teorias, quando diferentes conjuntos de observações não se equiparam aos dados preditos. As principais contribuições dos etologistas, além da descrição de algumas características gerais de estímulo-resposta (input, output), têm sido enriquecer o catálogo de comportamentos observados em ampla variedade de animais, sob várias condições naturais, e enfatizar os papéis de forças interativas, ecológicas e evolutivas que causam tais comportamentos. 
Instinto, Etologia e a Teoria de Konrad Lorenz

\section{Críticas à teoria de Lorenz}

O assunto sobre comportamento inato ou instintivo tem sido atualmente objeto de estudo minucioso. Beach (1955 citado por GRIER, 1984), revisou sistematicamente o conceito de instinto. Schleidt (1961) observou que a reação de escape de filhotes de peru a silhuetas de falcões envolve aprendizado e habituação, respondendo a qualquer novo objeto que passe sobre suas cabeças até que se habituem às formas familiares. Hailman (1967) demonstrou o envolvimento do aprendizado no desenvolvimento da busca de alimento. O próprio Lorenz (1965) admite concordar com a concepção dos behavioristas de que a dicotomia entre os elementos comportamentais inatos e aprendidos não é analiticamente válida. A dicotomia representa apenas o resultado da origem da questão; até então a única definição de inato é a de que não é aprendido, e vice-versa. Além disso, Lehrman (1953 citado por LORENZ, 1965), afirma que a existência de elementos comportamentais que não dependem de aprendizado não significa que estes podem ser, simplesmente, classificados como inatos, em função da não impossibilidade de excluir a participação do aprendizado nos processos ontogenéticos no ovo ou no útero, os quais são inacessíveis à observação. Lorenz (1965) ainda destaca que os tipos de comportamento, formalmente descritos como inatos ou aprendidos, representam apenas duas extremidades de uma graduação contínua, nas quais todas as possíveis interações podem ser observadas.

Estudos quantitativos mais cuidadosos têm mostrado que o comportamento é menos constante do que o padrão fixo de ação sugerido por Lorenz (1965). Nesse sentido, Barlow (1977, 1968 citado por GRIER, 1984), adaptou a idéia de Lorenz, diminuindo a exigência de estereotipagem, criando um novo termo Padrão de Ação Modal (MAP). Dewsbury (1978 citado por GRIER, 1984), na tentativa de esclarecer a definição ambígua de padrão fixo de ação, comparou 10 fontes de 11 atributos do conceito. Ele observou que parece haver pouca unanimidade de opiniões acerca do termo e concluiu que esse não deveria ser usado em comunicações científicas. As noções associadas com energia específica de ação, mecanismo desencadeador inato e conceitos similares têm sido substancialmente rejeitados por serem muito vagos e não sustentados por fundamentos neurológicos (ANDREW, 1974; MC FARLAND e SIBLY 1972; HINDE, 1970, 1956; LEHRMAN, 1953 citados por GRIER, 1984).

Hoje, sabe-se que existem centros hipotalâmicos para controlar a alimentação, a sede, o comportamento sexual, materno, dentre outros. Tais comportamentos são desencadeados a partir da estimulação de centros excitatórios e finalizados ou evitados a partir de centros inibitórios (DETHIER e STELLAR, 1988). Entretanto, Lorenz (1995) acreditava que todo comportamento era controlado por um mecanismo apenas inibidor.

Discutindo a motivação para um determinado comportamento (energia específica de ação), Hinde, (1970 citado por GRIER, 1984), destacou vários problemas que se sobrepõem em alguma extensão: a) Motivações geralmente não são definidas independentemente das variações no comportamento; estas são supostas para explicar aquelas. Pode existir, por exemplo, muita circularidade na definição de sede como uma tendência para beber, ou seja, a definição dessa motivação depende das variações do comportamento consumatório - pouca sede, bebe-se pouco; muita sede, bebe-se muito. b) O grau de correlação da motivação com o comportamento pode depender de quais aspectos do comportamento são medidos e como eles são medidos. Diferentes medidas do mesmo aspecto do comportamento, geralmente, produzem 
resultados diversos. c) Motivação tem sido definida de diferentes maneiras por diferentes autores. Por essa razão, a terminologia é ambígua. d) Não está claro qual nível de motivação para o comportamento deve ser aplicado. No comportamento de construção de ninho, por exemplo, há motivação para reprodução, para construção de ninho, para carregar gravetos, ou para tudo isso? O uso do conceito de motivação pode ser uma simplificação e pode obscurecer o que realmente está ocorrendo. A motivação pode ser ilusória. Um pesquisador pode apenas observar o fato ou prover explicações detalhadas de coisas que nem sempre existem.

Hinde (1970) concluiu que o conceito de motivação apresenta uma faixa de utilidade limitada e pode ser enganosa e perigosa se usada erroneamente. Mais tarde, ele nota que isso é verdadeiro não só para o conceito de motivação como, também, para todos os conceitos explicativos. Em 1981, o próprio Lorenz (1995) critica o modelo hidromecânico, propondo modificações. O modelo original implica equivocadamente uma diferença qualitativa entre os estímulos endógenos que completam o reservatório do potencial específico de ação (PEA) e aqueles que finalmente desencadeiam o comportamento (estímulos externos). Na verdade, esses estímulos divergem apenas quantitativamente, pois ambos contribuem para a elevação do PEA e o desencadeamento do comportamento, conforme o modelo modificado na figura 1b. O novo modelo sugere que a abertura da válvula é afetada apenas pela pressão no interior do reservatório (altura da coluna), onde o limiar é constante e está simbolizado nas espirais, cuja tensão não é influenciada por qualquer agente externo. Os estímulos libertadores diferem daqueles que aumentam latentemente a prontidão apenas em relação ao tempo necessário para efetuar o comportamento. Nesse modelo ainda está representado o efeito adicional dos estímulos não específicos libertadores de prontidão (ELP), pela adição de novas torneiras, que elevam o nível da água (PEA). O próprio autor destaca que o modelo modificado poderia aproximar-se mais dos processos fisiológicos reais, adicionando-se um dispositivo que representasse o fenômeno da inércia na abertura e fechamento da válvula.

\section{Aspectos gerais atuais acerca do estudo do comportamento animal}

De acordo com Carthy (1980), a compreensão moderna do comportamento instintivo surgiu por meio da investigação experimental direta de padrões complexos de comportamento. Hoje, as unidades científicas - escolas - de pensamento dos etologistas europeus, que investigam o comportamento em condições naturais ou seminaturais, bem como a dos psicólogos e fisiólogos americanos, que têm estado interessados em um aspecto limitado do comportamento, observado em condições artificiais de laboratório, estão convergindo em suas investigações experimentais. Apesar das diferenças dessas duas escolas científicas, é notável a semelhança dos seus achados e concepções básicas.

Desde meados da década de 1950, a distinção entre etologia e psicologia comparada vem desaparecendo lentamente. Os primeiros etologistas acreditavam que a maior parte do comportamento animal era instintivo ou pré-programado, e não era afetado, em grande extensão, pela experiência. Os psicólogos reivindicavam que o aprendizado e a experiência eram os principais determinantes do comportamento. Hoje, a maioria dos estudiosos do comportamento animal acredita que nenhum desses pontos de vista está completamente correto, e o 
atual foco está centrado nas interações entre genótipo/ambiente, fisiologia e experiência como determinantes do comportamento (DRICKAMER, VESSEY e MEIKLE, 1996). Estudiosos do comportamento animal têm testemunhado a emergência de um número de subcampos com nomes que prometem uma integração de aspectos psicológicos e biológicos de mecanismos de processamento de informações e tomadas de decisões pelos animais. Shettleworth (2001) cita a etologia cognitiva de Griffin (1978) e Ristau (1991), a ecologia cognitiva de Real (1993) e Dukas (1988), a psicologia evolucionária de Daly e Wilson (1999) e a cognição comparativa de Wasserman (1993).

A aplicação de teorias e métodos da psicologia cognitiva para análise das causas de comportamentos que ocorrem naturalmente tem aumentado. Ao mesmo tempo, modelos funcionais estão surgindo para explicar como os processos cognitivos ocorrem, como a neurobiologia e métodos comparativos modernos. A combinação de diversos aspectos de áreas de pesquisas interdisciplinares da cognição animal pode resultar em um tipo de sinergismo (SHETTLEWORTH, 2001). Segundo essa autora, os possíveis benefícios da interação entre aspectos psicológicos e biológicos da cognição animal têm sido discutidos por Shettleworth (1998, 1984), Kamil (1988), Rozin e Schull (1988) e Stamps (1991). Contudo, algumas barreiras à comunicação interdisciplinar foram apontadas por Kamil e Yoerg (1982 citados por SHETTLEWORTH, 2001), como as diferenças de terminologia e atitudes das pesquisas laboratoriais versus trabalhos de campo.

O desenvolvimento da ecologia comportamental, da etologia e da cognição comparativa, nos últimos anos, tem contribuído para enriquecer o menu de mecanismos cognitivos e problemas funcionais, destacados por Shettleworth (2001). Hoje, é sabido que as concepções que as pessoas têm em relação ao comportamento e às funções cognitivas em animais, tornaram-se um tema relevante para a compreensão do relacionamento entre outros animais e seres humanos, com implicações epistemológicas.

Para concluir, entende-se que, ao se compreenderem os mecanismos que determinam os padrões de comportamento natural dos animais e suas respectivas funções, que lhes conferem valor adaptativo para sobrevivência, os programas de conservação, produção animal, criação em cativeiro (zoológicos), relação médico-paciente (veterinária) e de educação ambiental poderão ser eficientemente desenvolvidos, respeitando-se os aspectos psicobiológicos das espécies.

Prada (1997) nos deixa um "recado" ao dizer que cabe a nós, enquanto humanidade, munidos de uma "evolução" cultural, tecnológica e pensando já em tecnociência, respeitarmos os animais como seres viventes, também dotados de "alma", de um mundo que já lhes pertencia muito antes de aqui chegarmos, como pretensiosos senhores de tudo e de todos. 
Zuanon, Á. C. A.

\section{Referências}

AMABIS, J. M.; MARTHO, G. R. Biologia das populações: genética, evolução biológica, ecologia. 2. ed. São Paulo: Editora Moderna, 2005.

CARTHY, J. D. Observação e descrição do comportamento. In: Comportamento animal. São Paulo: EPU/Editora da Universidade de São Paulo, 1980. p. 1-8.

CUNHA, W. H. A. Introdução ao desenvolvimento histórico e aos princípios básicos da etologia. In: ENCONTRO PAULISTA DE ETOLOGIA, 1., 1983, Jaboticabal. Anais... Jaboticabal, 1983. p. 1-33.

Convite-justificativa para o estudo naturalístico do comportamento animal. Jornal Brasileiro de Psicologia, São Paulo, v. 1, n. 2, p. 37-57, 1965.

DETHIER, V. G.; STELLAR, E. Comportamento animal. Trad. Diva Diniz Corrêa. São Paulo: Edgard Blücher, 1988.

DRICKAMER, L. C.; VESSEY, S. H.; MEIKLE, D. Animal behavior: mechanisms ecology - evolution. Dubuque: Wm. C. Brown Publishers, 1996.

FERrEIRA, A. B. H. Dicionário Aurélio Básico da Língua Portuguesa. São Paulo: Folha de São Paulo, 1995.

GRIER, J. W. Biology of animal behavior. St. Louis: Times Mirror/Mosby College Publishing, 1984.

HAILMAN, J. P. The ontogeny of an instinct: the pecking response in chicks of the laughing gull (Larus atricilla L.) and related species. Leiden: E. J. Brill, 1967. Behav. Suppl. XV.

HESS, E. H. Etologia e psicologia do desenvolvimento. In: CARMICHAEL, L. Manual de psicologia da criança. São Paulo: EPU, 1975. p. 1-59.

HINDE, R. A. Animal behaviour: a synthesis of Ethology and comparative Psychology.

2. ed. London: McGraw-Hill, 1970.

KAMIL, A. C. A synthetic approach to the study of animal intelligence. In: LEGER, D. W. (Ed.). Comparative perspectives on modern Psychology. Lincoln: University of Nebraska Press, 1988. p. 230-257.

LORENZ, K. Os fundamentos da etologia. São Paulo: Editora da Universidade Estadual Paulista, 1995.

Companions as factors in the bird's environment: the conspecific as the eliciting factor for social behaviour patterns. 1935. In: Studies in animal and human behaviour. Cambridge: Harvard University Press, 1970. p. 101-258. v. I. 
Instinto, Etologia e a Teoria de Konrad Lorenz

Evolution and modification of behavior. Chicago: The University of Chicago

Press, 1965.

. The comparative method in studying innate behaviour patterns. In: SYMPOSIUM

OF THE SOCIETY FOR EXPERIMENTAL BIOLOGY, 4., 1950. p. 221-268.

MATIOLI, S. R. Biologia molecular e evolução. Ribeirão Preto: Editora Holos, 2001.

PAVLOV, I. P. Conditioned reflexes. London: Oxford University Press, 1927.

PRADA, I. L. S. A alma dos animais. São Paulo: Editora Mantiqueira, 1997.

ROSS, S.; DENENBERG, V. H. Innate behavior: the organism in its enviroment. In: WATERS, R. H.; TETHLINGSHAFFER, D. A.; CALDWELL, W. E. Principles of comparative psychology. Nova York: McGraw-Hill, 1960. p. 43-73.

ROZIN, P.; SCHULL, J. The adaptive-evolutionary point of view in experimental psychology. In: ATKINSON, R.; HERRNSTEIN, R. J.; LINDZEY, G.; LUCE, R. D. (Eds.). S. S. Stevens' Handbook of Experimental Psychology. New York: J. Wiley, 1988. p. 503-546.

SHETTLEWORTH, S. J. Animal cognition and animal behaviour. Animal Behaviour, Amsterdam, v. 61, n. 2, p. 277-286, 2001.

Cognition, evolution and behavior. New York: Oxford University Press, 1998.

Learning and behavioral ecology. In: KREBS, J. R.; DAVIES, N. B. (Eds.).

Behavioural Ecology. Oxford: Blackwell Scientific, 1984. p. 170-194.

SCHLEIDT, W. M. Reaktionen von Truthühnern auf fliegende Raubvögel und Versuche zur Analyse ihrer. AAM's. Zeits. f. Tierpsych, n. 18, p. 534-560, 1961.

STAMPS, J. A. Why evolutionary issues are reviving interest in proximate behavioral mechanisms. American Zoologist, n. 31, p. 338-348, 1991.

WUNDT, W. Grundriss der psychologie. Leipzig: Alfred Kröner Verlag, 1922.

Artigo recebido em janeiro de 2007 e aceito em julho de 2007.

349

Ciência $\mathfrak{E}$ Educação, v. 13, n. 3, p. 337-349, 2007 